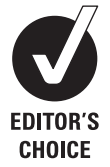

'Oslo Sports Trauma Research Center, Department of Sports Medicine, Norwegian School of Sports Sciences, Oslo Sports Trauma Research Center, Oslo, Norway ${ }^{2}$ Medical and Scientific Department, International Olympic Committee, Lausanne, Switzerland ${ }^{3}$ Orthopeadic Surgery, University of Oslo, Oslo, Norway

\section{Correspondence to}

Kathrin Steffen, Department of Sports Medicine, Norwegian School of Sports Sciences, Oslo Sports Trauma Research Center, PO 4014 Ullevål Stadion, Oslo, Norway, 806; kathrin.steffen@nih.no

Received 12 March 2012 Accepted 12 March 2012

\title{
Health protection of the Olympic athlete
}

\author{
Kathrin Steffen, ${ }^{1,2}$ Torbjørn Soligard, ${ }^{2}$ Lars Engebretsen ${ }^{1,2,3}$
}

\section{ABSTRACT}

Protection of the athletes' health is a clearly articulated objective of the International Olympic Committee. Longitudinal surveillance of injuries and illnesses can provide valuable data that may identify high-risk sports and disciplines. This is a foundation for introducing tailored preventive measures. During the XXIX Summer and XXI Winter Games, comprehensive injury and illness recording through the medical staff of the participating National Olympic Committees and the sports medicine clinics revealed that between $7 \%$ and $11 \%$ of all athletes incurred an injury or suffered from at least one occurrence of illness during the Games. The incidence of injuries and illnesses varied substantially between sports. In the future, risk factor and injury mechanism analyses in high-risk Olympic sports are essential to better direct injury-prevention strategies. Concomitantly, periodic health evaluations of athletes will be instrumental to optimise health protection.

\section{INTRODUCTION}

With almost 11000 expected athletes from more than 200 countries, the XXX London 2012 Olympic Games will be one of the largest sports events ever. More than 2500 athletes participated in the XXI Winter Olympic Games held in Vancouver in 2010. The protection of an athlete's health is an important task for the International Olympic Committee (IOC). ${ }^{1}$ Systematic injury and illness surveillance monitoring over long periods of time, and the identification of high-risk sports, including the most common and severe injuries and illnesses, is a starting place from which to address injury-prevention occurrence. ${ }^{2} 3$ Following the six-stage Translating Research into Injury Prevention Practice (TRIPP) model of Finch, ${ }^{4}$ analysing the extent of a problem such as high injury and/or illness risk in a specific population, is the first step in the development of effective prevention strategies (figure 1).

The IOC injury and illness surveillance system, developed in cooperation with the International Sports Federations (IFs) and National Olympic Committees (NOCs), was successfully implemented in the 2008 Beijing (injury surveillance only) ${ }^{2}$ and in the 2010 Vancouver Olympics (injury and illness surveillance). ${ }^{3}$ It will be further developed and optimised in the 2012 London and 2014 Sochi Olympic Games. ${ }^{5}$ Major sport events, such as the Olympic Games, constitute an ideal environment for instituting such surveillance. The study population is a relatively homogenous group in terms of skill level, and the study period is defined by the event itself, which is usually characterised by a high standard of environmental factors (eg, safety of venues, optimal preparation of training and competition facilities). ${ }^{67}$ As early as 1998, the Fédération Internationale de Football Association (FIFA) started to survey all injuries incurring during their competitions, ${ }^{68-11}$ and other major sports federations followed FIFA's Medical Assessment and Research Centre (F-MARC) lead. ${ }^{12-16}$ Based on these experiences, a group of experts, convened by the IOC, developed an injury surveillance for multisport events. ${ }^{17}$ During the 2008 Beijing Olympic Games, the IOC performed surveillance on all sports for the first time. ${ }^{2}$

Continuous injury and illness surveillance during major sporting events will build a foundation for providing evidence for the development of injury-prevention programs. ${ }^{1}$ The aim of the present paper was to summarise the injuries and illnesses that occurred in the previous two Olympic Games to enable the NOC physicians and medical personnel better prepare for the 2012 London Olympic Games. Practical implications and suggestions for further research to protect the athletes' health are provided.

\section{METHODS}

In Beijing and Vancouver, all NOCs' head physicians participated in the Olympic surveillance studies and reported daily on the occurrence (or non occurrence) of newly sustained injuries and illnesses (only injuries in Beijing) on a standardised reporting form. The injury definition and data-collection procedures are described comprehensively elsewhere. ${ }^{2} 317$ In addition, information on all athletes treated for injuries and illnesses by the Local Organising Committee medical services were retrieved from the available medical centres located at selected venues. Athletes seen for an injury or illness in the venue medical stations or the central clinics were reported through the central clinic database.

\section{Injury and illness report form}

The report form on injuries and illnesses required broad documentation of the respective injury and illness. Detailed instructions on how to fill out the form correctly were given in the booklet with examples for injuries and illnesses. Daily injury information was also received from the polyclinics in the Olympic Villages. Injury and illness report forms were distributed to the NOCs in all required languages. ${ }^{2} 317$

\section{Definition of injury and illness}

An athlete was defined as injured or ill if he/she received medical attention regardless of the consequences with respect to absence from competition or training. Following the IOC injury-surveillance 


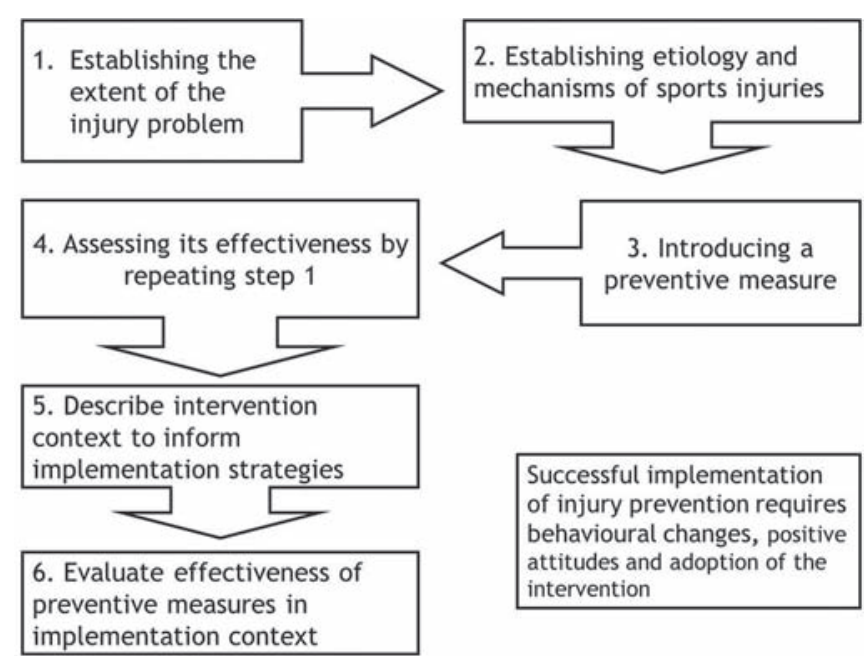

Figure 1 TRIPP model: framework for research leading to sports injury prevention. ${ }^{4}$

system, an injury should be reported if it fulfilled the following criteria: (1) musculoskeletal complaint or concussion, (2) newly incurred (pre-existing, not fully rehabilitated should not be reported) or re-injuries (if the athlete has returned to full participation after the previous injury), (3) occurred in competition or training and (4) occurred during the XXIX Summer Olympic Games 2008 (August 9-24, 2008) or the XXI Winter Olympic Games 2010 (February 12-28, 2010). An illness was defined as any physical complaint (not related to injury) newly occurred during the Games that received medical attention regardless of the consequences with respect to absence from competition or training. ${ }^{3}$

All information was handled confidentially and the injury reports were anonymised after the Olympic Games. Ethical approval was obtained by the Regional Committee for Medical Research Ethics, Region $\varnothing$ st-Norge, Norway.

\section{RESULTS}

\section{Response rate and coverage of the athletes}

All NOCs with more than 50 (Beijing) or 10 registered athletes (Vancouver) were included in the analysis of response rate, and these countries represented more than $94 \%$ of all participating athletes. ${ }^{2} 3$ In Beijing, the head physicians of all the participating NOCs returned a total 1050 injury report forms (72\%). In addition, 264 injury report forms were received from medical stations at the different Olympic venues and through daily reports from the polyclinic in the Olympic Village. ${ }^{2}$ Throughout the 17 days of the Vancouver Olympics, the 33 participating NOCs (with more than 10 athletes) returned a total of 461 out of a maximum of 561 forms (82\%). ${ }^{3}$ In both Olympic Games, the response rate of completed forms by the NOC head physicians decreased with the size of the NOCs (defined by the number of participating athletes).

\section{Injury risk in different sports}

In the two Olympics, the overall injury rate was similar at around $10 \%$ of registered athletes sustaining at least one injury (table 1). The incidence of injuries varied substantially among the different sports, both in Beijing and in Vancouver (table 2). The risk of sustaining an injury was highest for football, taekwondo, field hockey, handball, weightlifting and boxing in Beijing (all $\geq 15 \%$ of the athletes). ${ }^{2}$ In Vancouver, injury risk was highest for bobsleigh, ice hockey, short track, alpine and for freestyle and snowboard cross $(15 \%-35 \%$ of registered athletes were affected in each sport). ${ }^{3}$

\section{Injury location and type}

In Beijing, the distribution of injuries was as follows: about half of the diagnoses (54\%) affected the lower extremity, 20\% were related to the upper extremity, $13 \%$ to the trunk and $12 \%$ to the head/neck. The thigh (13\%) and knee $(12 \%)$ were most commonly injured, followed by the lower leg, ankle and head injuries (9\%). ${ }^{2}$ In Vancouver, for both genders, the face, head and cervical spine (female 20\%, male 21\%) and knee (female $16 \%$, male $11 \%$ ) were the most prominent injury locations. In alpine, freestyle and snowboarding, 22 out of 102 injuries (22\%) affected the head/cervical spine and one quarter of all injuries affected the knee (24\%). Twenty concussions were reported, affecting $7 \%$ of the registered athletes. A death occurred in luge. ${ }^{3}$

\section{Injury mechanism, circumstance and severity}

In Beijing, one third of the 1055 injuries (33\%) were caused by contact with another athlete. Non-contact trauma $(20 \%)$ and overuse either with gradual $(9 \%)$ or sudden onset $(13 \%)$ were also frequent causes of injury. ${ }^{2}$ In Vancouver, the three

Table 1 Comparison of injury risk between the 2008 Beijing $^{2}$ and 2010 Vancouver ${ }^{3}$ Olympic Games

\begin{tabular}{|c|c|c|}
\hline & Beijing 2008 & Vancouver 2010 \\
\hline Participating athletes & 10977 & 2567 \\
\hline Injuries (per 1000 athletes) & $1055(96.1)$ & $287(111.8)$ \\
\hline Most common diagnosis & Ankle sprains (7\%), thigh strains $(7 \%)$ & Concussions $(7 \%)$ \\
\hline Most affected locations & Trunk $(13 \%)$, thigh $(13 \%)$, head/neck $(12 \%)$, knee $(12 \%)$ & Head/neck (16\%), knee (14\%), thigh (7\%) \\
\hline Most common mechanisms & $\begin{array}{l}\text { Non-contact }(20 \%) \text {, overuse }(22 \%) \text {, contact with } \\
\text { another athletes }(33 \%)\end{array}$ & $\begin{array}{l}\text { Contact with another athlete }(15 \%) \text {, contact with a stagnant } \\
\text { object }(22 \%) \text {, non-contact }(23 \%)\end{array}$ \\
\hline Expected time-loss injuries & $50 \%$ & $23 \% *$ \\
\hline Competition - training injuries & $73 \%-27 \%$ & $46 \%-54 \%$ \\
\hline High-risk sports (injuries per 100 athletes) & Football, taekwondo, field hockey, handball, weightlifting & $\begin{array}{l}\text { Snowboard cross, freestyle aerials and cross, bobsleigh, } \\
\text { ice hockey }\end{array}$ \\
\hline Low-risk sports (injuries per 100 athletes) & $\begin{array}{l}\text { Canoeing/kayaking, diving, rowing, sailing, synchronised } \\
\text { swimming, fencing }\end{array}$ & Nordic skiing disciplines, curling, speed skating \\
\hline
\end{tabular}

*This figure may underestimate the number of time-loss injuries as the response rate to this information was low and many of the injuries were of severe outcome, without estimated time loss registered (more details in the Vancouver paper). ${ }^{3}$ 
Table 2 Injury distribution of injuries from sports registered during the 2008 Summer Olympics ( $n=1055$ injuries) and 2010 Winter Olympics ( $n=287$ injuries)

\begin{tabular}{|c|c|c|c|c|}
\hline Olympic sports & $\begin{array}{l}\text { Registered } \\
\text { athletes }\end{array}$ & $\begin{array}{l}\text { Number of } \\
\text { injuries }\end{array}$ & $\begin{array}{l}\text { Percentage of } \\
\text { all injuries }\end{array}$ & $\begin{array}{l}\text { Percentage of } \\
\text { participating } \\
\text { athletes }\end{array}$ \\
\hline Alpine skiing & 308 & 46 & 3.5 & 14.9 \\
\hline Archery & 128 & 9 & 0.7 & 7.0 \\
\hline Athletics & 2132 & 241 & 18.3 & 11.3 \\
\hline Badminton & 172 & 8 & 0.6 & 4.7 \\
\hline Baseball & 189 & 21 & 1.6 & 11.1 \\
\hline Basketball & 287 & 38 & 2.9 & 13.2 \\
\hline Beach volleyball & 96 & 8 & 0.6 & 8.3 \\
\hline Biathlon & 202 & 3 & 0.2 & 1.5 \\
\hline Bobsleigh & 159 & 32 & 2.4 & 20.0 \\
\hline Boxing & 281 & 42 & 3.2 & 14.9 \\
\hline Canoeing/kayaking & 324 & 4 & 0.3 & 1.2 \\
\hline Cross-country skiing & 292 & 9 & 0.7 & 3.1 \\
\hline Curling & 100 & 4 & 0.3 & 4.0 \\
\hline Cycling & 518 & 30 & 2.2 & 5.8 \\
\hline Diving & 145 & 3 & 0.3 & 2.1 \\
\hline Equestrian & 193 & 10 & 0.8 & 5.2 \\
\hline Fencing & 206 & 5 & 0.4 & 2.4 \\
\hline Field hockey & 382 & 78 & 5.9 & 20.4 \\
\hline Figure skating & 146 & 21 & 1.6 & 14.3 \\
\hline Freestyle aerials & 47 & 9 & 0.7 & 19.1 \\
\hline Freestyle cross & 68 & 13 & 1.0 & 19.0 \\
\hline Freestyle moguls & 57 & 1 & 0 & 1.8 \\
\hline Gymnastics & 318 & 24 & 1.8 & 7.5 \\
\hline Handball & 334 & 58 & 4.4 & 17.4 \\
\hline Ice hockey & 444 & 82 & 6.2 & 18.5 \\
\hline Judo & 385 & 53 & 4.0 & 11.2 \\
\hline Luge & 108 & 2 & 0.1 & 1.9 \\
\hline Modern pentathlon & 71 & 4 & 0.3 & 5.6 \\
\hline Nordic combined & 52 & 1 & 0 & 1.9 \\
\hline Rowing & 548 & 10 & 0.8 & 1.8 \\
\hline Sailing & 400 & 3 & 0.2 & 0.8 \\
\hline Shooting & 386 & 3 & 0.2 & 7.8 \\
\hline Short track & 109 & 5 & 0.4 & 9.0 \\
\hline Skeleton & 47 & 3 & 0.3 & 6.4 \\
\hline Ski jumping & 67 & 3 & 0.3 & 4.5 \\
\hline Snowboard cross & 57 & 20 & 1.5 & 35.0 \\
\hline Snowboard half pipe & 69 & 9 & 0.7 & 13.0 \\
\hline Snowboard slalom & 59 & 4 & 0.3 & 6.8 \\
\hline Soccer & 496 & 156 & 11.8 & 31.5 \\
\hline Softball & 119 & 16 & 1.2 & 13.4 \\
\hline Speed skating & 176 & 5 & 0.4 & 2.8 \\
\hline Swimming & 1046 & 36 & 2.7 & 3.4 \\
\hline $\begin{array}{l}\text { Synchronised } \\
\text { swimming }\end{array}$ & 104 & 2 & 0.1 & 1.9 \\
\hline Table tennis & 172 & 9 & 0.7 & 5.2 \\
\hline Taekwondo & 126 & 34 & 2.6 & 27.0 \\
\hline Tennis & 168 & 10 & 0.8 & 5.9 \\
\hline Triathlon & 109 & 10 & 0.8 & 9.2 \\
\hline Volleyball & 287 & 23 & 1.7 & 8.0 \\
\hline Water polo & 259 & 25 & 1.9 & 9.7 \\
\hline Weightlifting & 255 & 43 & 3.3 & 16.9 \\
\hline Wrestling & 341 & 32 & 2.4 & 9.4 \\
\hline Total & $13544^{*}$ & $1320 \dagger$ & 100.0 & 10.8 \\
\hline
\end{tabular}

Sport is missing for $* 22$ injuries and +20 athletes. most common reported injury mechanisms were a non-contact trauma $(23 \%)$, contact with a stagnant object $(22 \%)$ and contact with another athlete (15\%) (table 1$).{ }^{3}$ While $73 \%$ of the injuries in Beijing occurred in the competition, ${ }^{2}$ in total 287 injuries in Vancouver were evenly distributed between official training $(54 \%)$ and competition $(46 \%)(\mathrm{p}=.18){ }^{3}$

In Beijing, about half of the injuries were expected to prevent the athletes from further training or competition $(50 \%)$. Physicians estimated that one third of the injuries would result in an absence from sport with up to 1 week. ${ }^{2}$ In Vancouver, of the 287 injuries, 65 (23\%) were expected to result in a timeloss situation for the athlete. Of those with expected time loss, 11 injuries (17\%) had an estimated absence from training or competition of more than 1 week (table 1). ${ }^{3}$

\section{Incidence and distribution of illnesses (registered in Vancouver only)}

Among 173 out of 2567 athletes (7\%) in Vancouver, a total of 185 illnesses were reported, resulting in an incidence of 72.1 illnesses per 1000 athletes. Illnesses were reported from a variety of sports, and they mostly (63\%) affected the respiratory system. The most frequent diagnosis was upper respiratory tract infection (pharyngitis, sinusitis, tonsillitis; $54 \%$ ).

\section{DISCUSSION}

This paper summarises the first two IOC surveillance projects and provides a direct comparison of the injury and illness occurrence of athletes between the 2008 Beijing Summer and 2010 Vancouver Winter Olympic Games. The findings show that of all participating athletes in the two most recent Olympic Games, about 10\% and 7\% suffered an injury or an illness, respectively. Certain team sports (such as soccer, ice hockey, field hockey, handball and basketball), martial art or weight class sports (such as taekwondo, boxing and weightlifting) and speed sports (such as bobsleigh and the skiing and snowboard disciplines) emerge as sports with high injury risk. ${ }^{23}$ Upper respiratory tract infection was the major cause of illness during the Vancouver Games. ${ }^{3}$

\section{Incidence and distribution, type and cause of injuries}

In Vancouver, the injury incidence was slightly higher than reported from the Summer Olympics in Beijing 2008 (111.8 vs 96.1 injuries per 1000 athletes). ${ }^{3}$ As illustrated for Winter sports by Torjussen and Bahr ${ }^{17}$ and for Summer sports by Junge et al, 617 choosing the appropriate method to report the risk of injury in sports is challenging if one is comparing different sports or disciplines where exposure may differ considerably. During the Olympics, for example, athletes may perform 15 jumps in a high jump competition, take eight throws in a javelin competition, do one ski run in a $50 \mathrm{~km}$ cross-country race, five runs in snowboard cross, play several matches in soccer, basketball, or ice hockey and 'only' one to four starts in a $100 \mathrm{~m}$ sprint competition. Thus, as an alternative to relative injury risk where the risk is expressed as rate corrected for exposure, for example, injuries per playing hours/matches/ runs, using the absolute injury risk is highly relevant for the present summary, where injuries and illnesses are expressed as the total number of injuries/illnesses per registered athletes for each sport/discipline. ${ }^{3}$

Having this in mind, athletics, soccer and ice hockey caused the greatest portion of injuries in the 2008 Summer $^{2}$ and 2010 Winter Olympics. ${ }^{3}$ However, this does not necessarily mean that athletes in these sports were at the greatest risk of injury. 
The explanation is that these sports have a great number of competing participants. When calculating the injury risk in relation to the number of participating athletes, the picture is somewhat different. In Beijing, the risk of sustaining an injury was highest for soccer, taekwondo, field hockey, handball, weightlifting, boxing, basketball and athletics. ${ }^{2}$ These findings are consistent with the literature. ${ }^{611} 18-22$ In Vancouver, freestyle and snowboard cross, bobsleigh, ice hockey, short track and alpine skiing were the sports with the highest injury risk; ${ }^{3}$ this is consistent with new data from the FIS (The International Skiing Federation) injury-surveillance system. ${ }^{23-25}$

In both Summer and Winter sports, many of the injuries occur as a result from athlete-to-athlete contact, typical for team sports characterised by tackling. In addition to this, a lot of the winter sports also involve high speeds. In freestyle and snowboard cross, for example, athletes race while passing challenges such as turns, jumps and waves. Combined with the speed component, competing in heats may promote an additional risk-taking attitude for the athletes. ${ }^{24}$ Parallels can also be drawn to for example, velodrome and road cycling, when the athletes position themselves for the final sprint. However, overuse injuries constitute a high proportion of injuries in sports as swimming, ${ }^{13}$ athletics, ${ }^{12}$ beach volleyball ${ }^{14}$ and cycling. ${ }^{26}$ Capturing overuse injuries, including their injury mechanisms through the current injury surveillance methodology is still a challenge and a new standardised methodology to quantify overuse injuries in surveillance studies needs to be developed. ${ }^{27}$

The lowest injury risk during the Beijing Olympics was observed for water sports such as sailing, canoeing/kayaking, rowing, synchronised swimming, diving and swimming, ${ }^{2}$ which extends the findings in these sports at non-Olympic settings. ${ }^{21} 2228$ The low injury risk for athletes competing in the Nordic skiing disciplines compared with alpine, freestyle and snowboard athletes is not surprising as they are not exposed to high speed on icy surfaces with minimal protection. ${ }^{24} 29$

In Vancouver, a major concern was that every fifth injury affected the head, neck and cervical spine, mainly diagnosed as abrasion, skin lesion, contusion, fracture or concussion. The figures for concussions were twice as high as reported from the Summer Olympic Games. ${ }^{2}$ Consequently, identifying mechanisms for concussion incidents should be of major importance. In many cases, head and knee injuries result in long absence from training and competition, and the prevention of concussions and severe knee ligament sprains, including anterior cruciate ligament ruptures, is important.

\section{Incidence and distribution, type and cause of illnesses (registered in Vancouver only)}

The incidence of illnesses from Vancouver is comparable with data from athletics (7\%), ${ }^{12}$ aquatics $(7 \%)^{13}$ and football $(12 \%) .{ }^{11}$ Almost two thirds of the illnesses affected the respiratory system $(62 \%)$ caused by infections $(64 \%)$, which is a higher rate than reported in swimming (respiratory system $50 \%$, infection $49 \%) .{ }^{13}$ Airway inflammation has been shown to often affect elite swimmers, ice-hockey players and cross-country skiers. ${ }^{30}$ It has been documented that good sanitation, early recognition and isolation of ill players can successfully reduce infections and illness in a team setting. ${ }^{31}$

\section{Practical implications and further research}

Introducing and implementing successful preventive measures relies, in part (eg, importance of compliance), ${ }^{4}$ on the proper characterisation of risk factors and mechanisms. ${ }^{32}$ Two recent reports describing situations leading to serious injuries in World Cup alpine skiing and snowboarding revealed that individual technical errors and inappropriate tactical choices ${ }^{33}$ and technical errors at take-off for jumping ${ }^{29}$ were primary causes of the injuries. These studies implicate that closer evaluations are necessary on course design and setting, race conditions, visibility and speed, and other technically difficult obstacles, such as height and distance between jumps. ${ }^{29} 34$

Analysing the inciting event of an injury, the moment when the injury occurs, will also be crucial for the better understanding of high-risk injury situations in Summer sports. Two main injury mechanisms have been identified for anterior cruciate ligament injury; one is during plant and cut and one-legged jump shot landings in team handball and basketball, the other when a large valgus force is combined with internal tibial rotation with the knee close to full extension. ${ }^{35} 36$

Hamstring strain injuries, typically occur during maximal acceleration and deceleration movements. A recent paper showed that hamstring muscles are most susceptible to strain injuries during the late swing phase of sprinting. ${ }^{37}$ Video analysis reveals that they occur during the final eccentric phase of the swing phase strike. This suggests that preventive measures should focus on eccentric hamstring strengthening exercises. $^{38}$

By using video analysis and a model-based image-matching technique, detailed information on joint kinematics can be obtained from uncalibrated injury video recordings. ${ }^{39}$ This approach will help to better understand injury mechanisms and optimise preventive tools. The IOC research group is now analysing the most serious injuries sustained in Vancouver in an effort to improve the knowledge on injury risk factors and mechanisms in high-risk sports. A similar project will be started after the London Games to analyse high-risk Summer sports.

As the causes and mechanisms of an injury vary substantially between sports, successful preventive strategies need to be tailored to the respective sport and athlete at risk. ${ }^{2} 40$ The effect of potential measures to reduce injury risk will be monitored in upcoming Games.

As a new initiative to early address the next generation of future Olympic athletes, the IOC has created a new sporting event for young athletes. The first Summer Youth Olympic Games were held in Singapore in August 2010, and the first Winter Youth Olympic Games in Innsbruck, Austria in January 2012. These events each bring together around 5000 athletes, aged 14-18, from all over the world to participate in high-level Olympic competitions. Little is known about the injury risk of the young athlete competing at high-level sports. ${ }^{40}$ Consequently, a comprehensive injury and illness surveillance, based on the IOC model for previous Olympic Games, was initiated during the 9 days of the 2012 first Winter Youth Olympic Games.

The IOC and other major IFs, such as the International Football Association (FIFA) ${ }^{11}$ the International Aquatic Federation (Fédération Internationale de Natation) ${ }^{13}$ and the International Association of Athletics Federations ${ }^{12}$ have extended their injury surveillance in a second step to also include illnesses monitoring. In addition, the IOC is currently looking into developing an Electronic Health Record system, to be offered to the NOCs to facilitate periodic health evaluations. This will increase the pre and in-Games knowledge both on injuries and illnesses, and will help the IOC and NOCs to maximise the health protection of their elite athletes. ${ }^{1}$ 
In London 2012, the IOC with the NOCs and IFs will continue running the injury- and illness- surveillance system. Following the data from Beijing ${ }^{2}$ and Vancouver, ${ }^{3}$ the monitoring of the athletes' health will enable researchers and clinicians to follow the injury and disease trends in the various sports and further the work of the IOC Medical Commission on protecting the health of the athletes. The message from this and other long-term projects initiated by the IOC and the IFs is that we need to monitor the development of injury and illness rates over several years to identify potential risk factor and mechanisms for injury and illnesses in disciplines and sports. By acquiring new knowledge on injury and illness trends, we can optimise and target future research on risk factors, mechanisms and finally, prevention. The key to a meaningful study of epidemiology lies in a well-organised procedure for data collection with coordinated efforts from sports medicine professionals, coaches and athletes, combined with systematic subsequent analyses.

\section{CONCLUSION}

The present data collection procedures were well accepted by the medical staff of the NOCs as demonstrated by the high response rates of injury and illness forms. Ten per cent of the athletes incurred an injury during the XXIX Summer or XXI Winter Games, and $7 \%$ of the winter sport athletes suffered from at least one illness. The incidence of injuries and illnesses varied substantially between sports. In the future, risk factor and video analyses of injury mechanisms in high-risk Olympic sports would permit better understanding of injury mechanisms and thus help to direct injury prevention strategies. Periodic health evaluations will be instrumental to preventing injuries and illnesses, and hence, to protect the health of the athletes.

Acknowledgements The research group wishes to acknowledge sincere gratefulness to the President of the IOC Medical Commission, Professor Arne Ljungqvist, and to NOCs and IFs for their strong support for these studies. The authors gratefully acknowledge the International Olympic Committee (IOC) for funding these studies. The authors also like to thank Professor Karim Khan for his valuable input to this paper.

\section{Competing interests None.}

Ethics approval All information was handled confidentially and the injury reports were anonymised after the Olympic Games. Ethical approval was obtained by the Regional Committee for Medical Research Ethics, Region Øst-Norge, Norway.

Provenance and peer review Commissioned; externally peer reviewed.

\section{REFERENCES}

1. Ljungqvist A, Jenoure $P$, Engebretsen $L$, et al. The International Olympic Committee (IOC) Consensus Statement on periodic health evaluation of elite athletes March 2009. Br J Sports Med 2009:43:631-43.

2. Junge A, Engebretsen L, Mountjoy ML, et al. Sports injuries during the Summer Olympic Games 2008. Am J Sports Med 2009;37:2165-72

3. Engebretsen L, Steffen K, Alonso JM, et al. Sports injuries and illnesses during the Winter Olympic Games 2010. Br J Sports Med 2010;44:772-80.

4. Finch C. A new framework for research leading to sports injury prevention. J Sci Med Sport 2006;9:3-9.

5. Steffen K, Soligard T, Engebretsen L. The IOC's endeavour to protect the health of the athlete continues. Br J Sports Med 2011;45:551-2.

6. Junge A, Langevoort G, Pipe A, et al. Injuries in team sport tournaments during the 2004 Olympic Games. Am J Sports Med 2006;34:565-76.

7. Alonso JM, Junge A, Renström P, et al. Sports injuries surveillance during the 2007 IAAF World Athletics Championships. Clin J Sport Med 2009;19:26-32.

8. Junge A, Dvorak J, Graf-Baumann T. Football injuries during the World Cup 2002 Am J Sports Med 2004;32(1 Suppl):23S-7S.
9. Junge A, Dvorak J, Graf-Baumann T, et al. Football injuries during FIFA tournaments and the Olympic Games, 1998-2001: development and implementation of an injuryreporting system. Am J Sports Med 2004;32(1 Suppl):80S-9S.

10. Yoon YS, Chai M, Shin DW. Football injuries at Asian tournaments. Am J Sports Med 2004; 32:36S-42S.

11. Dvorak J, Junge A, Derman W, et al. Injuries and illnesses of football players during the 2010 FIFA World Cup. Br J Sports Med 2011;45:626-30.

12. Alonso JM, Tscholl PM, Engebretsen L, et al. Occurrence of injuries and illnesses during the 2009 IAAF World Athletics Championships. Br J Sports Med 2010;44:1100-5

13. Mountjoy M, Junge A, Alonso JM, et al. Sports injuries and illnesses in the 2009 FINA World Championships (Aquatics). Br J Sports Med 2010:44:522-7.

14. Bahr R, Reeser JC; Fédération Internationale de Volleyball. Injuries among worldclass professional beach volleyball players. The Fédération Internationale de Volleyball beach volleyball injury study. Am J Sports Med 2003;31:119-25.

15. Fuller CW, Laborde F, Leather RJ, et al. International Rugby Board Rugby World Cup 2007 injury surveillance study. Br J Sports Med 2008;42:452-9.

16. Langevoort G, Myklebust G, Dvorak J, et al. Handball injuries during major international tournaments. Scand J Med Sci Sports 2007;17:400-7.

17. Junge A, Engebretsen L, Alonso JM, et al. Injury surveillance in multi-sport events: the International Olympic Committee approach. Br J Sports Med 2008:42:413-21.

18. Torjussen J, Bahr R. Injuries among elite snowboarders (FIS Snowboard World Cup). Br J Sports Med 2006;40:230-4.

19. Junge $\mathbf{A}$, Dvorak J. Injuries in female football players in top-level international tournaments. Br J Sports Med 2007;41(Suppl 1):i3-7.

20. Junge A, Dvorak J. Injury risk of playing football in Futsal World Cups. Br J Sports Med 2010;44:1089-92.

21. Greene JJ, Bernhardt D. Medical coverage analysis for Wisconsin's Olympics: the Badger State Games. Wis Med J 1997; 96:41-4.

22. Martin RK, Yesalis CE, Foster D, et al. Sports injuries at the 1985 Junior Olympics. An epidemiologic analysis. Am J Sports Med 1987;15:603-8.

23. Flørenes TW, Heir S, Nordsletten L, et al. Injuries among World Cup freestyle skiers. Br J Sports Med 2010;44:803-8.

24. Flørenes TW, Nordsletten L, Heir S, et al. Injuries among World Cup ski and snowboard athletes. Scand J Med Sci Sports 2010;22:58-66.

25. Flørenes TW, Bere T, Nordsletten L, et al. Injuries among male and female World Cup alpine skiers. Br J Sports Med 2009;43:973-8.

26. Clarsen B, Krosshaug T, Bahr R. Overuse injuries in professional road cyclists. Am J Sports Med 2010;38:2494-501.

27. Bahr R. No injuries, but plenty of pain? On the methodology for recording overuse symptoms in sports. Br J Sports Med 2009;43:966-72.

28. Cunningham C, Cunningham $S$. Injury surveillance at a national multisport event Aust J Sci Med Sport 1996;28:50-6.

29. Bakken A, Bere T, Bahr R, et al. Mechanisms of injuries in World Cup Snowboard Cross: a systematic video analysis of 19 cases. Br J Sports Med 2011;45:1315-22.

30. Fitch KD. An overview of asthma and airway hyper-responsiveness in Olympic athletes. Br J Sports Med 2012;46 (In press).

31. Hanstad DV, Rønsen 0, Andersen SS, et al. Fit for the fight? IIInesses in the Norwegian team in the Vancouver Olympic Games. Br J Sports Med 2011;45:571-5.

32. van Mechelen W, Hlobil H, Kemper HC. Incidence, severity, aetiology and prevention of sports injuries. A review of concepts. Sports Med 1992;14:82-99.

33. Bere T, Flørenes TW, Krosshaug T, et al. Mechanisms of anterior cruciate ligament injury in World Cup alpine skiing: a systematic video analysis of 20 cases. Am J Sports Med 2011;39:1421-9.

34. Bere T, Flørenes TW, Krosshaug T, et al. Events leading to anterior cruciate ligament injury in World Cup Alpine Skiing: a systematic video analysis of 20 cases. Br J Sports Med 2011:45:1294-302.

35. Olsen $\mathbf{0 E}$, Myklebust G, Engebretsen L, et al. Injury mechanisms for anterior cruciate ligament injuries in team handball: a systematic video analysis. Am J Sports Med 2004;32:1002-12.

36. Koga H, Nakamae A, Shima Y, et al. Mechanisms for noncontact anterior cruciate ligament injuries: knee joint kinematics in 10 injury situations from female team handball and basketball. Am J Sports Med 2010;38:2218-25.

37. Chumanov ES, Schache AG, Heiderscheit BC, et al. Hamstrings are most susceptible to injury during the late swing phase of sprinting. Br J Sports Med 2012;46:90.

38. Arnason A, Andersen TE, Holme I, et al. Prevention of hamstring strains in elite soccer: an intervention study. Scand J Med Sci Sports 2008;18:40-8.

39. Krosshaug T, Nakamae A, Boden B, et al. Estimating 3D joint kinematics from video sequences of running and cutting maneuvers-assessing the accuracy of simple visual inspection. Gait Posture 2007:26:378-85.

40. Steffen K, Engebretsen L. More data needed on injury risk among young elite athletes. Br J Sports Med 2010;44:485-9. 